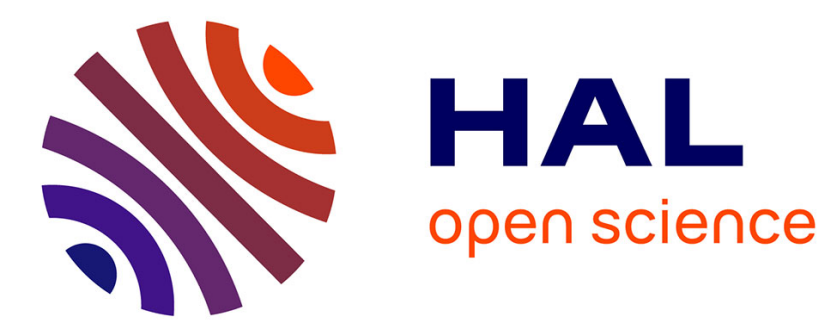

\title{
Polarized spectral properties and laser operation of Nd:SrAl12O19 crystal
}

Yuxin Pan, Bei Liu, Jian Liu, Qingsong Song, Jie Xu, Dongzhen Li, Peng Liu, Jie Ma, Xiaodong Xu, Hui Lin, et al.

\section{- To cite this version:}

Yuxin Pan, Bei Liu, Jian Liu, Qingsong Song, Jie Xu, et al.. Polarized spectral properties and laser operation of Nd:SrAl12O19 crystal. Journal of Luminescence, 2021, 235, pp.118034. 10.1016/j.jlumin.2021.118034 . hal-03227707

\section{HAL Id: hal-03227707 https://hal.science/hal-03227707}

Submitted on 8 Nov 2021

HAL is a multi-disciplinary open access archive for the deposit and dissemination of scientific research documents, whether they are published or not. The documents may come from teaching and research institutions in France or abroad, or from public or private research centers.
L'archive ouverte pluridisciplinaire HAL, est destinée au dépôt et à la diffusion de documents scientifiques de niveau recherche, publiés ou non, émanant des établissements d'enseignement et de recherche français ou étrangers, des laboratoires publics ou privés. 


\title{
Polarized spectral properties and laser operation of $\mathrm{Nd}: \mathrm{SrAl}_{12} \mathrm{O}_{19}$ crystal
}

\author{
YuXIN PAN, ${ }^{1,2}$ BeI LIU, ${ }^{1}$ JiAn LiU, ${ }^{3}$ QIngsong Song,${ }^{1}$ Jie XU, ${ }^{1}$ Dongzhen LI, ${ }^{1}$ \\ Peng LiU, ${ }^{1}$ Jie Ma, ${ }^{1}$ XiaOdong Xu, ${ }^{1,5}$ HuI LIN, ${ }^{2}$ Jun XU, ${ }^{3,6}$ AND KheIRREddine \\ LEBBOU ${ }^{4}$ \\ ${ }^{1}$ Jiangsu Key Laboratory of Advanced Laser Materials and Devices, School of Physics and Electronic \\ Engineering, Jiangsu Normal University, Xuzhou 221116, China \\ ${ }^{2}$ Engineering Research Center of Optical Instrument and System, Ministry of Education and Shanghai Key Lab of \\ Modern Optics and Systems, University of Shanghai for Science and Technology, 200093, China \\ ${ }^{3}$ School of Physics Science and Engineering, Institute for Advanced Study, Tongji University, Shanghai 200092, \\ China \\ ${ }^{4}$ Institut Lumière Matière, UMR5306 Université Lyon1-CNRS, Université de Lyon, Lyon 69622, Villeurbanne \\ Cedex, France \\ ${ }^{5}$ dxu79@jsnu.edu.cn \\ ${ }^{6}$ xujun@mail.shcnc.ac.cn
}

\begin{abstract}
Nd: $\mathrm{SrAl}_{11} \mathrm{O}_{19}$ (Nd:SRA) crystal has been grown by the Czochralski method. Polarized absorption spectra, polarized fluorescence spectra and fluorescence lifetime were investigated. For $\sigma$ polarization, the peak absorption cross section at $798 \mathrm{~nm}$ is $2.08 \times 10^{-20} \mathrm{~cm}^{2}$ with full width at half maximum (FWHM) of $10.2 \mathrm{~nm}$ and the peak emission cross section is $3.36 \times 10^{-20} \mathrm{~cm}^{2}$ at $1048.5 \mathrm{~nm}$ with FWHM of $4.80 \mathrm{~nm}$. The Judd-Ofelt parameters $\Omega_{2,4,6}$ were obtained to be $0.51 \times 10^{-20} \mathrm{~cm}^{2}$, $2.08 \times 10^{-20} \mathrm{~cm}^{2}$, and $2.12 \times 10^{-20} \mathrm{~cm}^{2}$, respectively. Continuous-wave laser operation of the a-cut and ccut Nd:SRA sample has been demonstrated. The maximum output power of $8.33 \mathrm{~W}$ was achieved from c-cut sample at an absorbed power of $27.73 \mathrm{~W}$, corresponding to a slope efficiency of $31.3 \%$.
\end{abstract}

Key words: Nd:SRA; Czochralski method; Judd-Ofelt theory; Continuous-wave laser

(C) 2020 Optical Society of America under the terms of the OSA Open Access Publishing Agreement

\section{Introduction}

Laser sources operating at $1.0 \mu \mathrm{m}$ wavelength region have attracted much attention due to their important applications, such as biology, medical detection, optical communication and scientific research [1-3]. In general, $1.0 \mu \mathrm{m}$ wavelength laser was realized in trivalent $\mathrm{Yb}^{3+}$ - and $\mathrm{Nd}^{3+}$-doped laser materials. Compared with $\mathrm{Yb}^{3+}$-doped gain materials, $\mathrm{Nd}^{3+}$-doped materials have relatively large emission cross section and negligible re-absorption loss due to their four-level operation. Among $\mathrm{Nd}^{3+}-$ doped laser crystals, Nd:YAG crystal has been proved to be excellent materials because of good physical and chemical properties. However, Nd:YAG crystal is limited to low $\mathrm{Nd}^{3+}$ doping concentration, narrow absorption and emission bandwidth, which causes a strong sensitivity to the pumping wavelength of AlGaAs laser diodes and limits the pulse width when used for mode-locked lasers. $\mathrm{Nd}^{3+}$-doped disordered crystals are promising in realizing mode-locked femtosecond laser, because they possess better thermal conductivity than Nd:glass and broader emission spectra than Nd:YAG crystal. In 2009, Xie et al. generated a passively mode-locked Nd:CLNGG disordered crystal laser with the pulse of $900 \mathrm{fs}$ [4]. Qin et al. demonstrated $\mathrm{Nd}, \mathrm{Y}: \mathrm{CaF}_{2}$ disordered crystal laser with pulse duration as short as $103 \mathrm{fs}$ [5]. Ma et al. achieved stable continuous-wave mode-locked pulses as short as 79 fs from $\mathrm{Nd}: \mathrm{Ca}_{3} \mathrm{La}_{2}\left(\mathrm{BO}_{3}\right)_{4}$ disordered crystal [6].

$\mathrm{SrAl}_{11} \mathrm{O}_{19}$ (SRA) crystallizes in the magneto-plumbite structure with the space group $\mathrm{P}_{3} / \mathrm{mmc}$ [7-9]. SRA crystal exhibits an excellent thermal conductivity of $11 \mathrm{~W} / \mathrm{m} \cdot \mathrm{K}$ and high Moh's hardness of 9 [10]. When it is doped with $\mathrm{Nd}^{3+}$ ion to form Nd:SRA, $\mathrm{Nd}^{3+}$ ion will replace the $\mathrm{Sr}^{2+}$ ion and charge compensation is achieved by substituting $\mathrm{Mg}^{2+}$ ion for $\mathrm{Al}^{3+}$ ion, which causes a complex and disordered lattice field in SRA crystal. In 1997, Verdun et al. reported the optical properties including absorption spectra and fluorescence lifetime of $\mathrm{Nd}^{3+}$-doped $\operatorname{SrAl}_{12} \mathrm{O}_{19}$ crystal grown by the laserheated pedestal-growth method [11]. Recently, we demonstrated a diode-pumped Nd:SRA $Q$-switched laser for the first time. A high repetition rate of $201 \mathrm{kHz}$ and a $Q$-switched pulse of $346 \mathrm{~ns}$ were obtained, with the peak power of $1.87 \mathrm{~W}$ and single pulse energy of $0.65 \mu \mathrm{J}$ [12]. 
In this work, Nd:SRA crystal has been grown by the Czochralski method. The polarized spectral of $\mathrm{Nd}$ :SRA crystal were studied. Using $800 \mathrm{~nm}$ laser diode as pumping source, the continuous-wave laser operation of Nd:SRA crystal was demonstrated.

\section{Crystal growth}

$\mathrm{Nd}$ :SRA crystal with $\mathrm{Nd}^{3+}$ concentration of 5 at.\% was grown using the Czochralski method. The $\mathrm{MgO}, \mathrm{SrCO}_{3}, \mathrm{Al}_{2} \mathrm{O}_{3}$ and $\mathrm{Nd}_{2} \mathrm{O}_{3}$ powders with purity of $99.999 \%$ were used as starting raw materials. They were dried and weighed according to a definite molar ratio. Due to the incongruent melting behavior, an excess of $\mathrm{SrCO}_{3}$ is required to obtain SRA single phase [13]. After the compounds were thoroughly mixed, they were pressed into pellet and then sintered at $1300{ }^{\circ} \mathrm{C}$ for $20 \mathrm{~h}$ in air atmosphere. The charge was then loaded into an iridium crucible for crystal growth. The growth direction was along the crystalline a-axis with the pulling rate of $1 \mathrm{~mm} / \mathrm{h}$ and rotation rate of $10-20 \mathrm{rpm}$. High-purity nitrogen gas was introduced in the growth chamber as a protective atmosphere. Fig. 1 shows the asgrown Nd:SRA crystal with the size of $\Phi 28 \times 40 \mathrm{~mm}^{3}$. The crystal boule is transparent pink color. Some inclusions at the end (Tail) of the boule were observed.

In order to confirm the structure of the as-grow Nd:SRA crystal, room temperature powder X-ray diffraction (XRD, Bruker-D2, Germany) at a scan width of $0.05^{\circ}$ with a range $2 \theta=10-80^{\circ}$ was performed. The XRD patterns of Nd:SRA crystal is displayed in Fig. 2. The diffraction peaks of the sample match well with the SRA standard card (JCPDS 80-1195). The data reveals that the as-grown $\mathrm{Nd}$ :SRA crystal possesses a hexagonal system with the space group of $\mathrm{P}_{3} / \mathrm{mmc}$. The cell parameters of Nd:SRA crystal were measured to be $a=b=5.5638(3) \AA, c=21.98558(5) \AA$. The $\mathrm{Nd}^{3+}$ ions concentration in Nd:SRA crystal was measured with an inductively coupled plasma atomic emission spectrometry (ICP-AES). The segregation coefficient of $\mathrm{Nd}^{3+}$ ions in Nd:SRA crystal was calculated to be arround 1.35 .

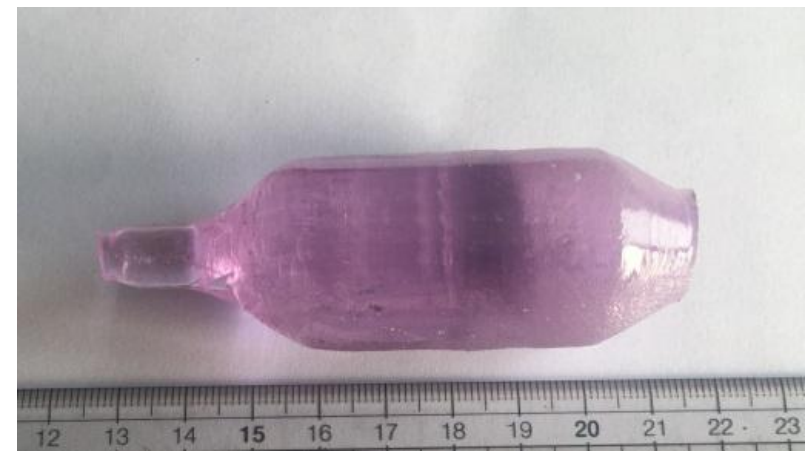

Fig. 1. As-grown single crystal ingot of Nd:SRA.

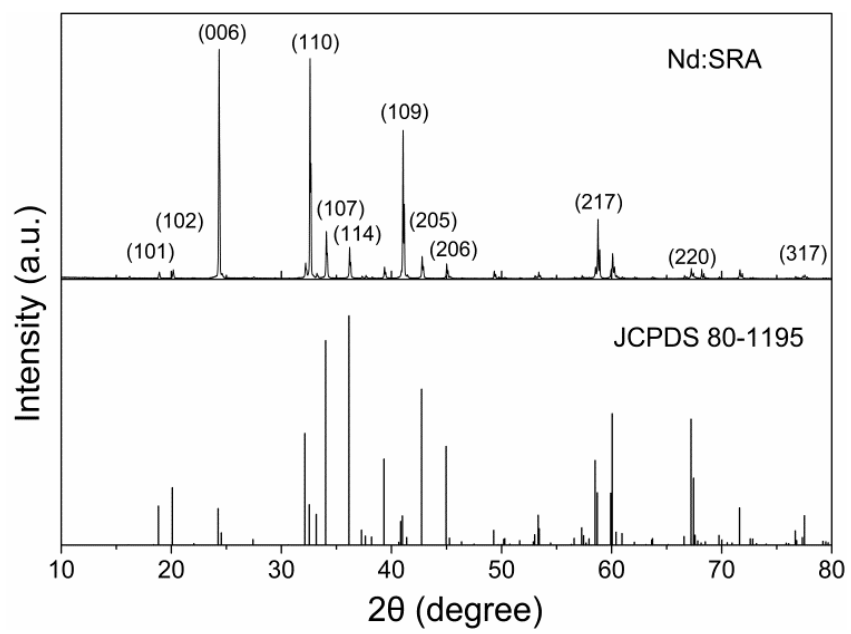

Fig. 2. Room temperature X-ray diffraction pattern of Nd:SRA crystal and standard pattern of SRA. 


\section{Spectral properties}

The crystal sample for spectroscopic measurements was cut from the as-grown Nd:SRA crystal, and the surfaces perpendicular to the $\left\langle 100>\right.$ growth axis were polished. The selected $\mathrm{Nd}^{3+}$ dopant concentration has been chosen to avoid strong emission quenching. The polarized absorption spectra were measured with a UV/VIS/NIR spectrophotometer (Model Cary-5000, Varian, USA) at room temperature. The fluorescence spectra and the fluorescence lifetime were recorded with an Edinburg Instrument FLS980 fluorescence spectrometer under $796 \mathrm{~nm}$ excitation. All the measurements were taken at room temperature.

Fig. 3 presents the polarized absorption spectra of Nd:SRA crystal in the wavelength region of 300$1000 \mathrm{~nm}$. All the absorption bands corresponding to transitions from the ${ }^{4} \mathrm{I}_{9 / 2}$ ground state to the various excited states of $\mathrm{Nd}^{3+}$ ions are marked. The absorption spectra show strong polarization dependence due to the anisotropy of the crystal, and the absorption cross-section of the $\sigma$ polarization is much higher than that of the $\pi$ polarization. The absorption cross sections were calculated to be $2.08 \times 10^{-20}$ $\mathrm{cm}^{2}$ at $798 \mathrm{~nm}$ for $\sigma$ polarization and $0.21 \times 10^{-20} \mathrm{~cm}^{2}$ at $794 \mathrm{~nm}$ for $\pi$ polarization, with full width at half maximum (FWHM) of $10.2 \mathrm{~nm}$ and $23.4 \mathrm{~nm}$, respectively. The relatively large FWHM permits high conversion efficiency when pumped by $\mathrm{AlGaAs}$ laser diode. Besides, the absorption cross section for $\sigma$ polarization is comparable with that of $\mathrm{Nd}: \mathrm{Ca}_{0.7} \mathrm{La}_{0.3} \mathrm{Mg}_{0.3} \mathrm{Al}_{11.7} \mathrm{O}_{19}\left(2.18 \times 10^{-20} \mathrm{~cm}^{2}\right.$ at $792 \mathrm{~nm}$ [14]), but is much larger than the value of $\mathrm{Nd}: \mathrm{LaMgAl}_{11} \mathrm{O}_{19}\left(1.7 \times 10^{-20} \mathrm{~cm}^{2}\right.$ at $\left.795 \mathrm{~nm}[15]\right)$ and $\mathrm{Nd}: \mathrm{Sr}_{0.7} \mathrm{La}_{0.3} \mathrm{Mg}_{0.3} \mathrm{Al}_{11.7} \mathrm{O}_{19}\left(8.6 \times 10^{-21} \mathrm{~cm}^{2}\right.$ at $\left.792 \mathrm{~nm}[16]\right)$.

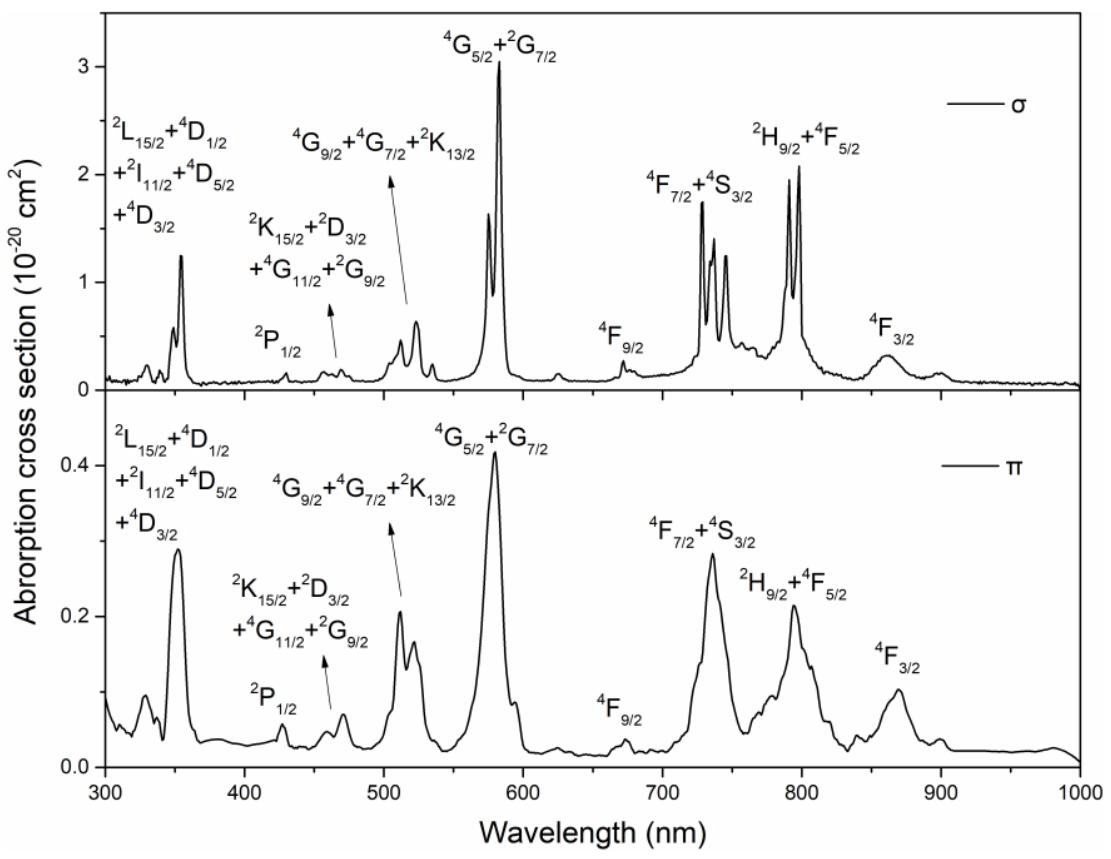

Fig. 3. Polarized absorption spectra of Nd:SRA crystal at room temperature.

The Judd-Ofelt theory $[17,18]$, which is the most popular and useful method for evaluating spectroscopic parameters of rare earth ions in materials, was applied in our paper. The reduced matrix elements used for absorption and emission transitions can be found in references [19] and [20], respectively. The J-O intensity parameters $\Omega_{2}, \Omega_{4}$ and $\Omega_{6}$ are listed in Table 1 . The effective J-O intensity parameters were calculated by $\Omega=\left(2 \Omega_{\sigma}+\Omega_{\pi}\right) / 3$, and the $\Omega_{2,4,6}$ were obtained to be $0.51 \times 10^{-20}$ $\mathrm{cm}^{2}, 2.08 \times 10^{-20} \mathrm{~cm}^{2}$, and $2.12 \times 10^{-20} \mathrm{~cm}^{2}$, respectively. In general, $\Omega_{2}$ is covalency-dependent parameter related to contravalency of the $\mathrm{Nd}^{3+}$ ion sites. Compared with $\mathrm{Nd}$ :YAG $\left(\Omega_{2,4,6}=0.2,2.7\right.$, and $5.0 \times 10^{-20} \mathrm{~cm}^{2}$ [21]), Nd:SRA has a relatively large $\Omega_{2}$ value, which indicates that the covalency of $\mathrm{Nd}$ :SRA is higher than that of Nd:YAG.

The spontaneous transition rate, branching ratios and the radiative lifetime of ${ }^{4} \mathrm{~F}_{3 / 2} \rightarrow{ }^{4} \mathrm{I}_{9 / 2}$, ${ }^{4} \mathrm{~F}_{3 / 2} \rightarrow{ }^{4} \mathrm{I}_{11 / 2},{ }^{4} \mathrm{~F}_{3 / 2} \rightarrow{ }^{4} \mathrm{I}_{13 / 2}$ and ${ }^{4} \mathrm{~F}_{3 / 2} \rightarrow{ }^{4} \mathrm{I}_{15 / 2}$ transitions of Nd:SRA crystal are given in Table 2 . We can see that the branching ratio of the ${ }^{4} \mathrm{~F}_{3 / 2} \rightarrow{ }^{4} \mathrm{I}_{9 / 2}$ transition is smaller than that of the ${ }^{4} \mathrm{~F}_{3 / 2} \rightarrow{ }^{4} \mathrm{I}_{11 / 2}$ transition for $\sigma$ polarization, but larger than that of the ${ }^{4} \mathrm{~F}_{3 / 2} \rightarrow{ }^{4} \mathrm{I}_{11 / 2}$ transition for $\pi$ polarization. The radiative lifetime of ${ }^{4} \mathrm{~F}_{3 / 2}$ energy level was calculated to be $552 \mu \mathrm{s}$, which is much longer than the value of $\mathrm{Nd}: \mathrm{Ca}_{0.7} \mathrm{La}_{0.3} \mathrm{Mg}_{0.3} \mathrm{Al}_{11.7} \mathrm{O}_{19}$ (364 $\mu$ s [14]), Nd:LaMgAl $\mathrm{I}_{11} \mathrm{O}_{19}$ (401 $\mu$ s [15), Nd: $\mathrm{Sr}_{0.7} \mathrm{La}_{0.3} \mathrm{Mg}_{0.3} \mathrm{Al}_{11.7} \mathrm{O}_{19}$ 
(500 $\mu$ s at $792 \mathrm{~nm}[16]), \mathrm{Nd}: \mathrm{KGd}\left(\mathrm{WO}_{4}\right)_{2}\left(111 \mu \mathrm{s}\right.$ [22]), Nd:Bi $\mathrm{Ge}_{3} \mathrm{O}_{12}(293 \mu \mathrm{s}$ [23]), and $\mathrm{Nd}: \mathrm{BaBi}_{2}\left(\mathrm{MoO}_{4}\right)_{4}(115 \mu \mathrm{s}[24])$. The results indicate that $\mathrm{Nd}$ :SRA crystal has a higher energy storge ability.

Table 1. The J-O intensity parameters of Nd:SRA crystal.

\begin{tabular}{cccc}
\hline Intensity parameter & \multicolumn{3}{c}{$\Omega\left(10^{-20} \mathrm{~cm}^{2}\right)$} \\
\cline { 2 - 4 } & $\sigma$-polarization & $\pi$-polarization & $\Omega=\left(2 \Omega_{\sigma}+\Omega_{\pi}\right) / 3$ \\
\hline$\Omega_{2}$ & 0.72 & 0.10 & 0.51 \\
$\Omega_{4}$ & 2.59 & 1.07 & 2.08 \\
$\Omega_{6}$ & 2.93 & 0.51 & 2.12 \\
\hline
\end{tabular}

Table 2. The spontaneous transition rate, branching ratios and radiative lifetime for different transition levels of Nd:SRA crystal.

\begin{tabular}{|c|c|c|c|c|}
\hline \multirow{2}{*}{$\begin{array}{l}\text { Transitions } \\
{ }^{4} \mathrm{~F}_{3 / 2} \rightarrow\end{array}$} & \multicolumn{2}{|c|}{$\sigma$-polarization } & \multicolumn{2}{|c|}{$\pi$-polarization } \\
\hline & $A_{\sigma}\left(S^{-1}\right)$ & $\beta_{\sigma}(\%)$ & $\mathrm{A}_{\pi}\left(\mathrm{S}^{-1}\right)$ & $\beta_{\pi}(\%)$ \\
\hline${ }^{4} I_{9 / 2}$ & 997.12 & 41.82 & 363.48 & 55.13 \\
\hline${ }^{4} \mathrm{I}_{11 / 2}$ & 1153.31 & 48.37 & 254.77 & 38.64 \\
\hline${ }^{4} \mathrm{I}_{13 / 2}$ & 229.22 & 9.61 & 40.19 & 6.10 \\
\hline${ }^{4} \mathrm{I}_{15 / 2}$ & 4.88 & 0.20 & 0.84 & 0.13 \\
\hline Radiative lifetime $(\mu \mathrm{s})$ & \multicolumn{4}{|c|}{$\tau_{\mathrm{rad}}=552$} \\
\hline
\end{tabular}

The polarized fluorescence spectra of Nd:SRA crystal in the range of 850-1450 nm was recorded under $796 \mathrm{~nm}$ excitation. The stimulated emission cross section can be calculated from the fluorescence spectra using the Füchtbauere Ladenburg (F-L) formula [25]. Fig. 4 presents the stimulated emission cross section for each polarization, and three emission bands are assigned to the transitions from ${ }^{4} \mathrm{~F}_{3 / 2}$ energy level to ${ }^{4} \mathrm{I}_{9 / 2},{ }^{4} \mathrm{I}_{11 / 2}$ and ${ }^{4} \mathrm{I}_{13 / 2}$ energy level, respectively. The emission cross section of the $\sigma$ polarization is larger than that of the $\pi$ polarization. The peak emission cross section was calculated to be $3.36 \times 10^{-20} \mathrm{~cm}^{2}$ for $\sigma$ polarization and $0.65 \times 10^{-20} \mathrm{~cm}^{2}$ for $\pi$ polarization both at $1048.5 \mathrm{~nm}$, respectively, with FWHM of 4.80 and $8.25 \mathrm{~nm}$. The emission cross section of ${ }^{4} \mathrm{~F}_{3 / 2} \rightarrow{ }^{4} \mathrm{I}_{11 / 2}$ transition for $\sigma$ polarization is smaller than the value of $\mathrm{Nd}: \mathrm{Ca}_{0.7} \mathrm{La}_{0.3} \mathrm{Mg}_{0.3} \mathrm{Al}_{11.7} \mathrm{O}_{19}\left(4.01 \times 10^{-21} \mathrm{~cm}^{2}\right.$ at $\left.1052 \mathrm{~nm}[14]\right)$ and $\mathrm{Nd}: \mathrm{LaMgAl}_{11} \mathrm{O}_{19}\left(4.08 \times 10^{-20} \mathrm{~cm}^{2}\right.$ at $1054.5 \mathrm{~nm} \mathrm{[15]).}$

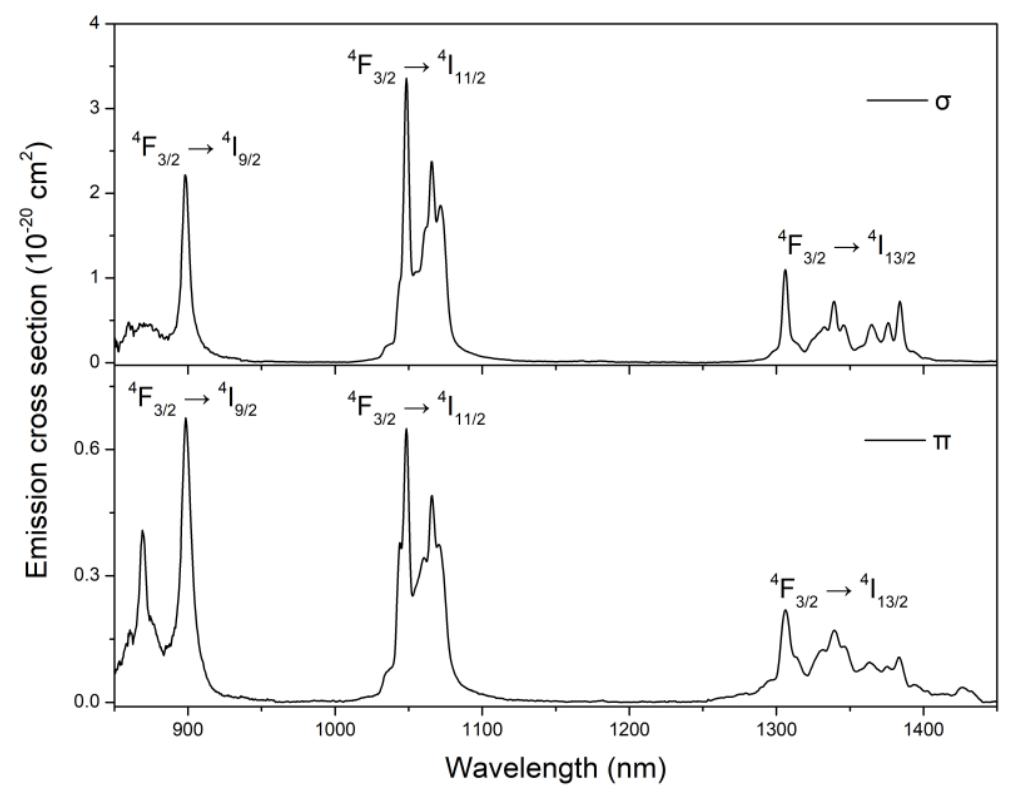

Fig. 4. Polarized emission spectra of Nd:SRA crystal excited by $796 \mathrm{~nm}$ at room temperature

Fig. 5 shows the fluorescence decay curve of the ${ }^{4} \mathrm{~F}_{3 / 2}$ multiplet. The decay curve shows a single exponential decaying behavior. The fluorescence lifetime was fitted to be $436 \mu \mathrm{s}$, which is much longer than that of $\mathrm{Nd}: \mathrm{Ca}_{0.7} \mathrm{La}_{0.3} \mathrm{Mg}_{0.3} \mathrm{Al}_{11.7} \mathrm{O}_{19}$ (333 $\mu$ s [14]), $\mathrm{Nd}: \mathrm{LaMgAl}_{11} \mathrm{O}_{19}(321 \mu \mathrm{s}$ [15),

$\mathrm{Nd}: \mathrm{Sr}_{0.7} \mathrm{La}_{0.3} \mathrm{Mg}_{0.3} \mathrm{Al}_{11.7} \mathrm{O}_{19}$ (372 $\mu$ s [16]), Nd:CaYAlO4 (129 $\mu \mathrm{s}$ [26]), Nd:GdNbO ${ }_{4}(178 \mu$ s [27]) and 
Nd:YAG (248 $\mu$ s [28]). According to the radiative lifetime from Table. 2, the luminescent quantum efficiency of the ${ }^{4} F_{3 / 2}$ level was calculated to be $79.0 \%$ by the equation of $\eta=\tau_{f} / \tau_{\text {rad }}$. The results show that Nd:SRA crystal is a promising gain medium for solid-state laser.

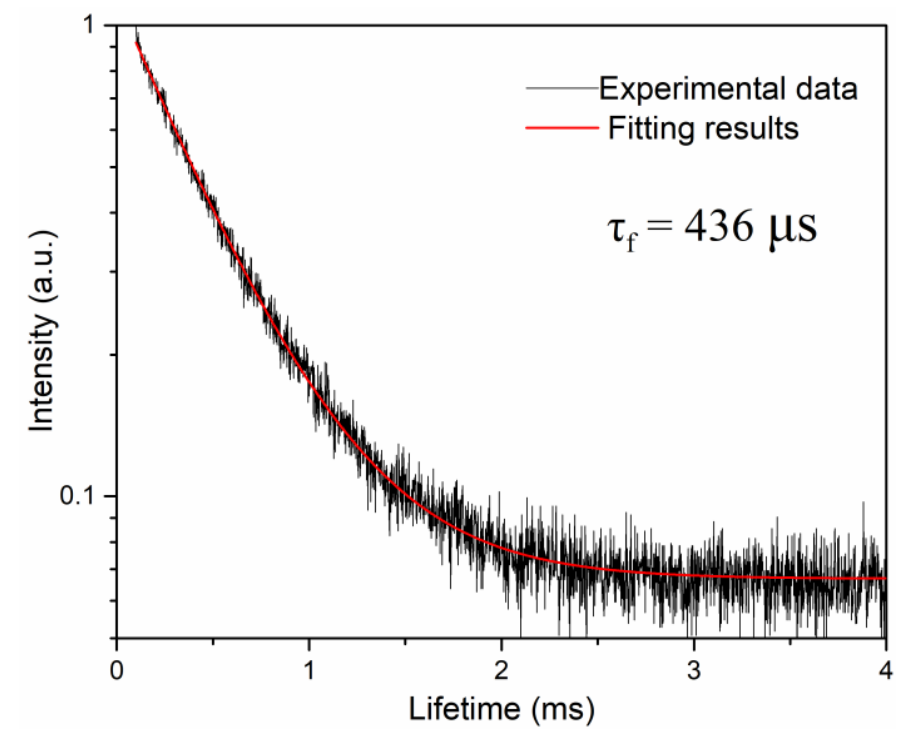

Fig. 5. The fluorescence decay curve of the ${ }^{4} \mathrm{~F}_{3 / 2}$ manifold of Nd:SRA

\section{Laser properties}

Samples used in the laser experiments were cut along $a$ and $c$ crystalline axis with dimensions of $3 \times 3$ $\times 6 \mathrm{~mm}^{3}$. The LD-pumped continuous-wave laser performance of Nd:SRA was carried out in a simple plano-plano resonator. The schematic diagram of the setup is the same as in [14]. The pump source was a fiber-coupled $800 \mathrm{~nm} \mathrm{AlGaAs} \mathrm{diode} \mathrm{laser} \mathrm{with} \mathrm{a} \mathrm{core} \mathrm{diameter} \mathrm{of} \mathrm{about} 200 \mu \mathrm{m}$ and a numerical aperture of 0.22 . Three different output couplers (OCs), with transmissions of $5 \%, 10 \%$ and $15 \%$ at $1049 \mathrm{~nm}$, were used in the experiments.

Fig. 6(a) shows the output power as a function of absorbed pump power of a-cut Nd:SRA laser. The threshold absorbed pump powers were 0.04, 0.099 and $0.05 \mathrm{~W}$, respectively, for the OCs with transmissions of $5 \%, 10 \%$ and $15 \%$. When the output coupler transmission was $10 \%$, a maximum output of $4.315 \mathrm{~W}$ was achieved at the absorbed pump power of $15.41 \mathrm{~W}$, corresponding to an opticalto-optical conversion efficiency of $28.0 \%$ and a slope efficiency of $28.8 \%$. The laser spectrum registered at maximum output power is shown in Fig. 6(b) with peak wavelength of about $1049.48 \mathrm{~nm}$.
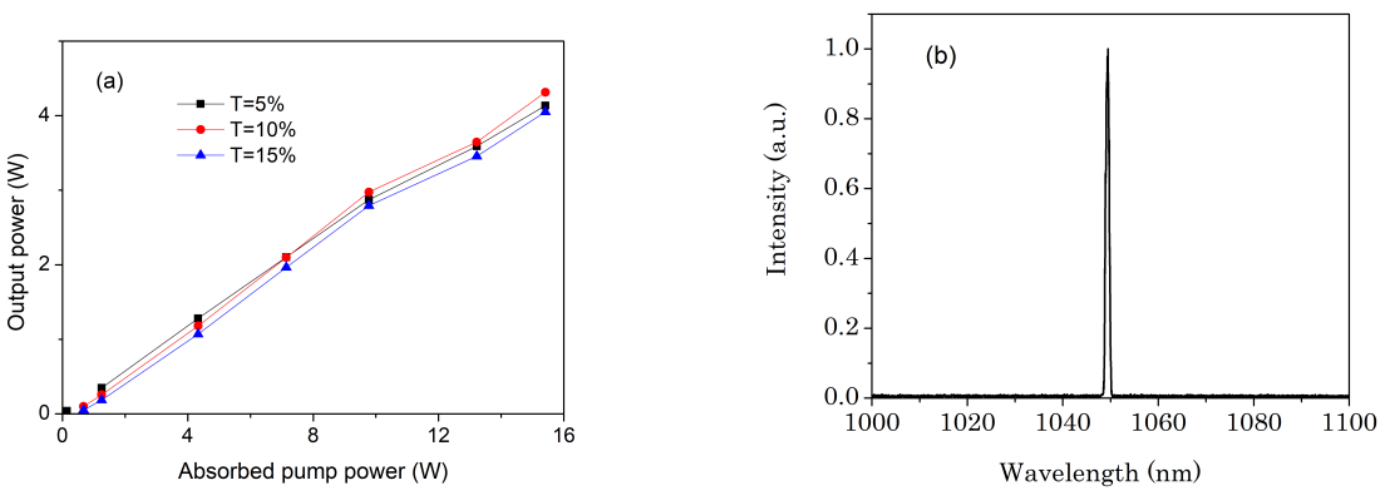

Fig. 6 (a)Output powers versus absorbed pump powers of doped-pumped a-cut Nd:SRA laser and (b) corresponding laser spectrum achieved at maximum output power

The dependence of the output power on the absorption pump power of c-cut Nd:SRA laser is illustrated in Fig. 7(a). Using the output coupler with transmission of 5\%, a maximum output power reached about $7.19 \mathrm{~W}$ with the threshold of about $0.061 \mathrm{~W}$ and the slope efficiency of about $26.8 \%$. Using the output coupler with transmission of $10 \%$, a maximum output power up to $8.25 \mathrm{~W}$ was 
achieved with the threshold of $0.032 \mathrm{~W}$ of absorbed power, which led to a slope efficiency of about $30.5 \%$. Using the output coupler with transmission of $15 \%$, the maximum output power increased to $8.33 \mathrm{~W}$ with the threshold of about $0.091 \mathrm{~W}$. The slope efficiency was linearly fitted to be about $31.3 \%$ and the corresponding optical-to-optical conversion efficiency was $30.0 \%$. The maximum output power of Nd:RSA is larger than that of $\mathrm{Nd}: \mathrm{Ca}_{0.7} \mathrm{La}_{0.3} \mathrm{Mg}_{0.3} \mathrm{Al}_{11.7} \mathrm{O}_{19}\left(5.40 \mathrm{~W}\right.$ [14]), Nd:LaMgAl $\mathrm{Al}_{11} \mathrm{O}_{19}(1.71 \mathrm{~W}$ [15), $\mathrm{Nd}: \mathrm{Sr}_{0.7} \mathrm{La}_{0.3} \mathrm{Mg}_{0.3} \mathrm{Al}_{11.7} \mathrm{O}_{19}$ (6.9 $\mathrm{W}$ [16]), but the slope efficiency of $\mathrm{Nd}: \mathrm{SRA}$ is lower than that of $\mathrm{Nd}: \mathrm{Ca}_{0.7} \mathrm{La}_{0.3} \mathrm{Mg}_{0.3} \mathrm{Al}_{11.7} \mathrm{O}_{19}$ (47.7\% [14]), Nd:LaMgAl ${ }_{11} \mathrm{O}_{19}$ (40.4\% [15), Nd:Sr $\mathrm{Sr}_{0.7} \mathrm{La}_{0.3} \mathrm{Mg}_{0.3} \mathrm{Al}_{11.7} \mathrm{O}_{19}$ (50\% [16]). At maximum output power, the peak wavelength was measured to be $1049.28 \mathrm{~nm}$ (see Fig. 7(b)). There was no pump saturation in our experiments, which indicates the output power can be further scaled with high pump power.
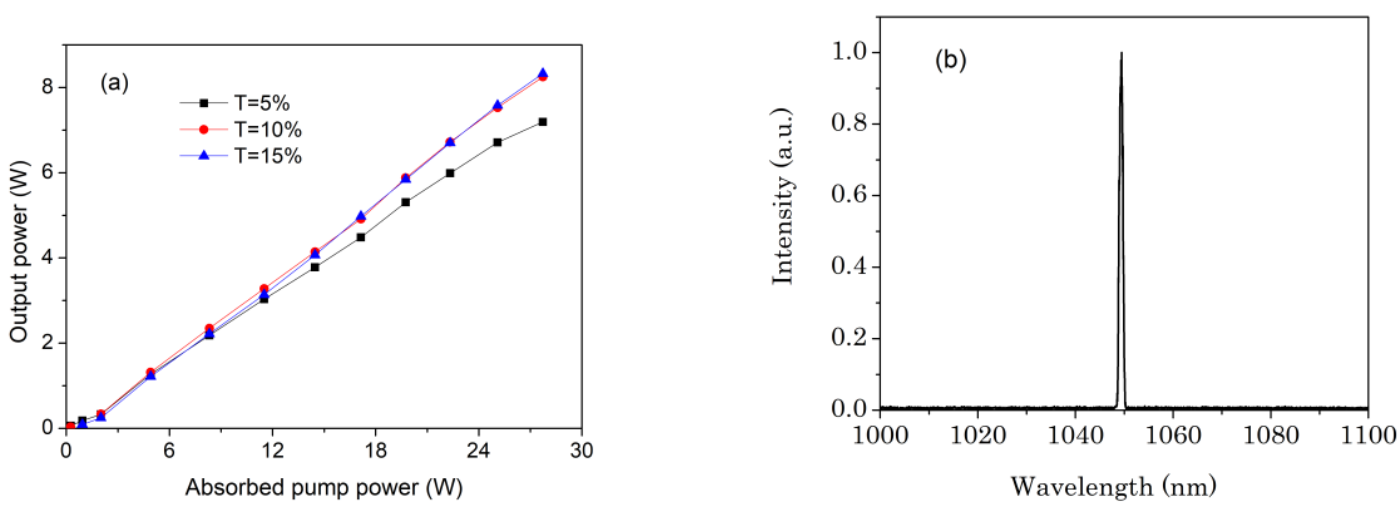

Fig. 7 (a)Output powers versus absorbed pump powers of doped-pumped c-cut Nd:SRA laser and (b) corresponding laser spectrum achieved at maximum output power

\section{Conclusions}

In conclusion, Nd:SRA crystal has been grown from the melt by Czochralski method. The crystal crystallizes in the hexagonal system with space group $\mathrm{P}_{3} / \mathrm{mmc}$. The cell parameters of Nd:SRA crystal were measured to be $a=b=5.5638 \AA, c=21.98558 \AA$. Polarized absorption spectra, polarized fluorescence spectra and fluorescence lifetime were investigated. The peak absorption cross-section was $2.08 \times 10^{-20}$ $\mathrm{cm}^{2}$ at $798 \mathrm{~nm}$ for $\sigma$ polarization, with the FWHM of $10.18 \mathrm{~nm}$. The effective intensity parameters $\Omega_{2,4,6}$ were obtained to be $0.51 \times 10^{-20} \mathrm{~cm}^{2}, 2.08 \times 10^{-20} \mathrm{~cm}^{2}$, and $2.12 \times 10^{-20} \mathrm{~cm}^{2}$, respectively. The peak emission cross section was $3.36 \times 10^{-20} \mathrm{~cm}^{2}$ for $\sigma$-polarization at $1048.5 \mathrm{~nm}$, with a FWHM of $4.80 \mathrm{~nm}$. The radiative and fluorescence lifetime are 552 and $436 \mu$ s, respectively, resulting in a quantum efficiency of $79.0 \%$. Continuous-wave laser operation of Nd:SRA under 800nm laser diode has been demonstrated. For a-cut sample, the maximum output power of $4.315 \mathrm{~W}$ was obtained at an absorbed power of $15.41 \mathrm{~W}$ with the $\mathrm{T}_{\mathrm{OC}}=10 \%$, corresponding to a slope efficiency of $28.8 \%$. For c-cut sample, the maximum output power of $8.33 \mathrm{~W}$ was obtained at an absorbed power of $27.73 \mathrm{~W}$ with the $\mathrm{T}_{\mathrm{OC}}=$ $15 \%$, corresponding to a slope efficiency of $31.3 \%$.

\section{Funding}

National Natural Science Foundation of China (No. 61621001) and "Qinglan Project" of the Young and Middle-aged Academic Leader of Jiangsu College and University.

Disclosures. The authors declare no conflicts of interest.

\section{References}

1. T. J. Kane, W. J. Kozlovshy, and R. I. Byer, "Coherent laser radar at $1.06 \mu \mathrm{m}$ using Nd:YAG lasers,” Opt. Lett. 12(4), 239-241 (1987).

2. K. Washio, "Neodymium-doped solid-state lasers and their applications to materials processing," Mater. Chem. Phys. 31(1-2), 57-66 (1992)

3. R. Moncorge, B. Chambon, J. Y. Rivoire, N. Garnier, E. Descroix, P. Laporte, H. Guillet, S. Roy, J. Mareschal, D. Pelenc, J. Doury, and P. Farge, "Nd doped crystals for medical laser applications," Opt. Mater. 8(1-2) 109-119 (1997)

4. G. Q. Xie, D. Y. Tang, W. D. Tan, H. Luo, H. J. Zhang, H. H. Yu, and J. Y. Wang, "Subpicosecond pulse generation from a Nd:CLNGG disordered crystal laser," Opt. Lett. 34(1), 103-105 (2009)

5. Z. P. Qin, G. Q. Xie, J. Ma, W. Y. Ge, P. Yuan, L. J. Qian, L. B. Su, D. P. Jiang, F. K. Ma, Q. Zhang, Y. X. Cao, and J. Xu, "Generation of $103 \mathrm{fs}$ mode-locked pulses by a gain linewidth-variable Nd,Y:CaF 2 disordered crystal," Opt. Lett. 39(7), 1737-1739 (2014) 
6. J. Ma, Z. B. Pan, H. Q. Cai, H. H. Yu, H. J. Zhang, D. Y Shen, and D. Y. Tang, "Sub-80 femtosecond pulses generation from a diode-pumped mode-locked Nd:Ca $\mathrm{Ca}_{3} \mathrm{La}_{2}\left(\mathrm{BO}_{3}\right)_{4}$ disordered crystal laser," Opt. Lett. 41(7), 1384-1387 (2016)

7. A. J. Lindop, C. Matthews, D. W. Goodwin, "Refined structure of $\mathrm{Sr}_{0.6} \mathrm{Al}_{2} \mathrm{O}_{3}$," Acta Crystallogr. B 31, $2940-2941$ (1975)

8. L. D. Merkle, B. Zandi, R. Moncorge, Y. Guyot, H. R. Verdun and B. Mclntosh, "Spectroscopy and laser operation of $\mathrm{Pr}, \mathrm{Mg}: \mathrm{SrAl}_{12} \mathrm{O}_{19}$,’ J. App. Phys. 79(4), 1849-1856 (1996)

9. J. Liu, Q. S. Song, D. Z. Li, X. D. Xu, and J. Xu, "Growth and red-orange emission of $\mathrm{Sm}^{3+} \mathrm{doped}^{\mathrm{SrAl}} \mathrm{H}_{12} \mathrm{O}_{19} \mathrm{single}$ crystals," Opt. Mater. 101, 109754 (2020)

10. M. Fechner, F. Reichert, N.-O. Hansen, K. Petermann, G. Huber, "Crystal growth, spectroscopy, and diode pumped laser performance of Pr,Mg:SrAl ${ }_{12} \mathrm{O}_{19}$," App. Phys. B 102, 731-735 (2011)

11. H. R. Verdum, D. E. Wortman, C. A. Morrison, and J. L. Bradshaw, "Optical properties of $\mathrm{Nd}^{3+}$ in single crystal $\mathrm{SrAl}_{12} \mathrm{O}_{19}$," Opt. Mater. 7. 117-128 (2007)

12. M. F. Zhao, Z. M. Zhang, X. Y. Feng, M. Y. Zong, J. Liu, X. D. Xu, and H. Zhang, "High repetition rate passively $Q$ switched laser on Nd:SRA at $1049 \mathrm{~nm}$ with MXene $\mathrm{Ti}_{3} \mathrm{C}_{2} \mathrm{~T}_{\mathrm{x}}$," Chin. Opt. Lett. 18(4), 041401 (2020)

13. F. Gantis, T. Y. Chemkova, and Y. P. Udalov, "Sr- $\mathrm{Al}_{2} \mathrm{O}_{3}$ system," Russ. J. Inorg. Chem., 24, 260 (1979)

14. Y. X. Pan, B. Liu, J. Liu, Q. S. Song, J. Xu, D. Z. Li, P. Liu, J. Ma, X. D. Xu, H. Lin, J. Xu, and K. Lebbou, "Spectroscopic properties and continuous-wave laser operation of $\mathrm{Nd}: \mathrm{Ca}_{0.7} \mathrm{La}_{0.3} \mathrm{Mg}_{0.3} \mathrm{Al}_{11.7} \mathrm{O}_{19}$," Opt. Mater. Express 10(5), $1255-1263$ (2020)

15. Y. X. Pan, S. D. Zhou, J. W. Wang, B. Xu, J. Liu, Q. S. Song, J. Xu, D. Z. Li, P. Liu, X. D. Xu, and J. Xu, "Growth, spectral properties, and diode-pumped laser operation of a $\mathrm{Nd}^{3+}$-doped $\mathrm{LaMgAl}_{11} \mathrm{O}_{19}$ crystal,” Appl. Opt. 57(32), 96579661 (2018).

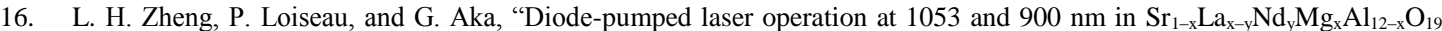
(Nd:ASL) single crystal," Laser Phys. 23(9), 095802 (2013).

17. B. R. Judd, "Optical absorption intensities of rare-earth ions," Phys. Rev. 127(3), 750-761 (1962).

18. G. S. Ofelt, "Intensities of crystal spectra of rare- earth ions," J. Chem. Phys. 37(3), 511-520 (1962).

19. W. T. Carnall, P. R. Fields, and K. Rajnak, "Energy levels in the Trivalent Lanthanide Aqua $\operatorname{Ions} \mathrm{I} \mathrm{Pr}^{3+}, \mathrm{Nd}^{3+}, \mathrm{Pm}^{3+}$, $\mathrm{Sm}^{3+}, \mathrm{Dy}^{3+}, \mathrm{Ho}^{3+}, \mathrm{Er}^{3+}$, and $\mathrm{Tm}^{3+}$, , J. Chem. Phys. 49(10), 4424-4442 (1968).

20. A. A. Kaminskii, G. Boulon, M. Buoncristiani, B. Di Bartolo, A. Kornienko, and V. Mironov, "Spectroscopy of a new laser garnet $\mathrm{Lu}_{3} \mathrm{Sc}_{2} \mathrm{Ga}_{3} \mathrm{O}_{12}: \mathrm{Nd}^{3+}$. Intensity luminescence characteristics, stimulated emission, and full set of squared reduced- matrix elements $\left|<\left\|U^{(t)}\right\|>\right|^{2}$ for $\mathrm{Nd}^{3+}$ ions," Phys. Status Solidi (a) 141(2), 471-494 (1994).

21. W. F. Krupke, "Radiative transition probabilities within ${ }^{4} \mathrm{~F}_{3}$ ground configuration of Nd-YAG," IEEE J. Quantum Electron. 7(4), 153 ( 1971)

22. Y. J. Chen, Y. F. Lim X. H. Gong, Q. G. Tan, J. Zhuang, Z. D. Luo, and Y. D. Huang, "Polarized spectroscopic properties of $\mathrm{Nd}^{3+}$-doped $\mathrm{KGd}\left(\mathrm{WO}_{4}\right)_{2}$ single crystal," J. Lumin. 126, 653-660 (2007)

23. N. Li, Y. Y. Xue, D. H. Wang, B. Liu, C. Guo, Q. S. Song, X. D. Xu, J. F. Liu, D. Z. Li, J. Xu, Z. A. Xu, and J. Y. Xu, "Optical properties of $\mathrm{Nd}: \mathrm{Bi}_{4} \mathrm{Ge}_{3} \mathrm{O}_{12}$ crystals grown by the micro-pulling-down method," J. Lumin. 206, 412-416 (2019)

24. A. V. Lebedev, S. A. Avanesov, V. A. Klimenko, L. V. Vasileva, and A. Hammoud, "Growth and spectroscopic studies of $\mathrm{Nd}^{3+}$-doped $\mathrm{BaBi}_{2}\left(\mathrm{MoO}_{4}\right)_{4}$ crystal," 103, 109901 (2020)

25. B. Aull and H. Jenssen, "Vibronic interactions in Nd:YAG resulting in nonreciprocity of absorption and stimulated emission cross sections," IEEE J. Quantum Electron. 18, 925-930 (1982).

26. D.Z Li, X.D. Xu, S.S. Cheng, D.H. Zhou, F. Wu, Z.W. Zhao, C.T. Xia, J. Xu, H.M. Zhu, and X.Y. Chen, "Polarized spectral properties of $\mathrm{Nd}^{3+}$ ions in $\mathrm{CaYAlO}_{4}$ crystal," Appl. Phys. B 101, 199-205 (2010)

27. S.J. Ding, F. Peng, Q.L. Zhang, J.Q. Luo, W.P. Liu, D.L. Sun, R.Q. Dou, J.Y. Gao, G.H. Sun, and M.J. Cheng, "Crystal growth, spectral properties, and continuous wave laser operation of Nd:GdNbO 4 ," J. Alloys Compd. 693, 339-343 (2017)

28. S. Singh, R.G. Smith, and L.G. Van Uitert, "Stimulated-emission cross section and fluorescent quantum efficiency of Nd ${ }^{3+}$ in yttrium aluminum garnet at room temperature,” Phys. Rev. B 10, 2566-2572 (1974) 